\title{
PENGARUH PEREGANGAN (STRETCHING) TERHADAP PENURUNAN NYERI DISMENORE
}

\author{
Sherkia Ichtiarsi Prakasiwi
}

Kebidanan, Fakultas IImu Keperawatan Dan Kesehatan, Universitas Muhammadiyah Semarang, Email: sherkia@unimus.ac.id

\section{INFO ARTIKEL}

Riwayat Artikel:

Diterima: 24-04-2020

Disetujui: 29-07-2020

\section{Kata Kunci:}

Peregangan

Remaja

Nyeri Dismenore

\section{A. LATAR BELAKANG}

Didunia diperkirakan kelompok remaja berjumlah 1,2 milyar atau $18 \%$ dari jumlah penduduk dunia (WHO, 2014). Kesehatan reproduksi remaja tidak hanya masalah seksual saja namun menyangkut segala aspek tentang reproduksinya. Pemahaman tentang menstruasi sangat diperlukan untuk dapat mendorong remaja yang mengalami ganguan menstruasi agar mengetahui dan mengambil sikap yang terbaik

\begin{abstract}
Abstrak: Dismenore merupakan masalah ginekologis yang paling umum dialami wanita, khususnya remaja. Prevalensi dismenore primer di Indonesia cukup tinggi yaitu $60-70 \%$ dan $15 \%$ diantaranya mengalami nyeri hebat yang umumnya terjadi pada usia remaja. Solusi non farmakologis dipandang lebih aman, salah satunya adalah peregangan yang bertujuan untuk membuat otot dan persendian menjadi fleksibel dan elastis. Hal ini disebabkan karena meningkatnya kadar endorphin, epinephrine, dopamine dan serotonin yang dihasilkan oleh otak akibat olahraga. Tujuan Penelitian: Menganalisis pengaruh peregangan terhadap penurunan tingkat nyeri dismenore pada santri putri di Pondok Pesantren As Salafiyyah Yogyakarta. Metode Penelitian : Penelitian ini menggunakan jenis quasi experiment dengan design Two Group Pre-test and Post-test. Sampel penelitian adalah santri putri berjumlah 30 responden pada kelompok kontrol dan 30 responden pada kelompok intervensi. Teknik pengambilan sampel yaitu purposive sampling, teknik analisis univariat menggunakan uji statistik distribusi frekuensi, analisis bivariat menggunakan uji statistik Mann Whitney dan multivariat menggunakan uji statistik regresi linier dengan menggunakan software SPSS. Hasil : Ada pengaruh peregangan terhadap penurunan nyeri dismenore dengan nilai $p$ value $=0,00<a(0,05)$ dan dimana nilai rata-rata sebelum diberikan peregangan rata-ratanya $5,13 \pm 3,99$ dan setelah diberikan peregangan rata rata nyerinya turun menjadi $0,13 \pm 1,60$, hal ini menunjukkan bahwa terdapat perbedaan tingkat nyeri dismenore sebelum dan setelah diberikan peregangan. Kesimpulan: Peregangan terbukti dapat menurunkan nyeri dismenore hingga 4,597 kali.
\end{abstract}

\begin{abstract}
Dysmenorrhea is the most common gynecological problems that women especially adolescent. The prevalence of primary dysmenorrhea in Indonesia is quite high, $60-70 \%$ and $15 \%$ of them experienced severe pain that usually occurs in adolescence. Nonpharmacological solutions is considered more secure, one of them is stretching, so that in any exercise aimed at making the muscles and joints become flexible and elastic. This is due to increased levels of endorphins, epinephrine, dopamine dan serotonin produced by exercise induced brain. Objective: To analyze influence of stretching on decrease pain on dysmenorrhea in women students in Pondok Pesantren As Salafiyyah Yogyakarta. Methods: This study used a quasi-experiment with design types two group pre-test and post-test. Samples were female students were 30 respondents in the control group and 30 respondents in the intervention group. The sampling technique is purposive sampling, analytical techniques univariate statistical test frequency distribution, bivariate analysis using statistical test Mann Whitney and multivariate linear regression using statistical tests using SPSS software. Results: There influence of stretching on decrease pain on dysmenorrhea with $p$ value $=0.00<a(0.05)$ and the average value before being given stretch averaged $5.13 \pm 3.99$ and after given stretch of average pain decreased to $0.13 \pm 1.60$, it indicates that there are differences in the level of pain of dysmenorrhea before and after a given stretch. Conclusion: Stretching is proven to decrease the pain of dysmenorrhea up to 4,597 times.
\end{abstract}

(Pusat Data dan Informasi Kemenkes RI, 2015). Menstruasi yang harus dialami para remaja wanita dapat menimbulkan masalah, salah satunya adalah Dismenore. Dismenore merupakan masalah ginekologis yang paling umum dialami wanita baik wanita dewasa maupun wanita pada usia remaja.

Nyeri haid/dismenore merupakan ketidakseimbangan hormon progesteron dalam darah sehingga mengakibatkan rasa nyeri timbul. Wanita pernah mengalami dismenore sebanyak $90 \%$, ini mengganggu $50 \%$ wanita masa reproduksi 
dan 60-85\% pada usia remaja, yang mengakibatkan banyaknya absensi pada sekolah maupun kantor (Annathayakheisha, 2009). Kejadian absensi disekolah dan saat bekerja dilaporkan terjadi sepertiga hingga setengah, terjadi $5 \%$ sampai $14 \%$ frekuensi absensi lebih sering terjadi (Exercise for dysmenorrhea (review), 2010). Dismenore diklasifikasikan menjadi dua, yaitu dismenore primer dan dismenore sekunder (Perry, 2010). Menurut Purnamasari (2013), dismenore yang banyak terjadi adalah dismenore primer yaitu sebanyak $54,89 \%$, sedangkan dismenore sekunder hanya $9,36 \%$.

Banyak cara mengatasi dismenore yaitu dengan cara farmakologis maupun non farmakologis. Solusi non farmakologis dipandang lebih aman karena tidak menimbulkan efek samping seperti obat-obatan (Ningsih, 2011). Masyarakat sudah mengetahui tentang dismenore, namun untuk mengatasi dengan cara peregangan (stretching) masih belum banyak mengetahuinya.

\section{B. METODE PENELITIAN}

Penelitian yang digunakan adalah penelitian kuantitatif menggunakan jenis penelitian quasi eksperimental. Sampel yang digunakan yaitu 60 responden, 30 responden pada kelompok intervensi dan 30 responden pada kelompok kontrol. Nyeri dismenore diukur dengan menggunakan alat ukur nyeri NRS (Numeric Rating Scale). Variabel yang diteliti adalah nyeri dismenore dan peregangan (stetching). Sampel pada penelitian ini adalah santriputri di tiga Pondok Pesantren di wilayah Sleman Yogyakarta. Populasi penelitian ini adalah santri putri yang ada di Pondok Pesantren As Salafiyyah, Al Idris, Assalimiyyah. Sampel dalam penelitian ini adalah santri putri yang mengalami nyeri dismenore. Teknik pengambilan sampel pada penelitian ini adalah purposive sampling suatu teknik penetapan sampel dengan cara memilih sampel diantara populasi. Analisis yang digunakan dalam penelitian ini adalah analisis univariat, tingkat nyeri dismenore disajikan dalam bentuk tabel distribusi frekuensi.

\section{HASIL DAN PEMBAHASAN}

TABEL 1.

Distribusi Frekuensi Berdasarkan Karakteristik Responden

\begin{tabular}{lcccc}
\hline \multirow{2}{*}{ Karakteristik } & \multicolumn{2}{c}{$\begin{array}{c}\text { Kelompok } \\
\text { Kontrol }\end{array}$} & \multicolumn{2}{c}{$\begin{array}{c}\text { Kelompok } \\
\text { Intervensi }\end{array}$} \\
\cline { 2 - 5 } & $\mathbf{n}$ & $\mathbf{\%}$ & $\mathbf{n}$ & $\mathbf{\%}$ \\
\hline Umur & & & & \\
13-17 tahun & 19 & 63,3 & 4 & 13,3 \\
18-22 tahun & 11 & 36,7 & 26 & 86,7 \\
Pendidikan & & & & \\
SMP & 3 & 10,0 & 0 & 0,0 \\
SMA & 16 & 53,3 & 5 & 16,7 \\
Mahasiswa & 11 & 36,7 & 25 & 83,3 \\
\hline
\end{tabular}

Tabel 1. menunjukkan bahwa prevalensi umur pada kelompok kontrol paling banyak pada kategori umur remaja awal 13-17 tahun yaitu sebanyak 19 (63,3\%) responden dan pada kelompok intervensi paling banyak pada kelompok umur remaja akhir 18-22 tahun yaitu sebanyak $26(83,3 \%)$ responden. Untuk variabel pendidikan pada kelompok kontrol paling banyak responden berpendidikan SMA yaitu sebanyak 16 $(53,3 \%)$ responden dan pada kelompok intervensi paling banyak pada kategori pendidikan sebagai Mahasiswa yaitu sebesar 25 (83,3\%).

TABEL 2.

Uji Homogenitas Subyek Penelitian

\begin{tabular}{lcc}
\hline \multicolumn{1}{c}{ Variabel } & n & p-value \\
\hline Umur & 60 & 0,105 \\
Pendidikan & 60 & 0,001 \\
\hline
\end{tabular}

Dari hasil analisis diatas didapatkan bahwa subyek penelitian yang homogen adalah pada variabel umur ( $\mathrm{p}$ value $>0,05)$. Sedangkan variabel pendidikan secara statistik tidak homogen ( $\mathrm{p}$ value $<0,05$ ).

Tabel1.3 Gambaran Tingkat Nyeri Dismenore Sebelum dan Sesudah Intervensi

TABEL 3 .

Gambaran Tingkat Nyeri Dismenore Sebelum Intervensi dan Sesudah Intervensi

\begin{tabular}{lcccc}
\hline \multicolumn{1}{c}{ Tingkat Nyeri } & \multicolumn{2}{c}{ Sebelum } & Sesudah & \\
& n & $\mathbf{9}$ & $\mathbf{n}$ & $\mathbf{\%}$ \\
\hline O Tdk Nyeri & O & o & 28 & 46,7 \\
1-3 (Ringan) & 19 & 31,7 & 12 & 20,0 \\
4-6 (Sedang) & 31 & 51,7 & 16 & 26,7 \\
7-9 (Berat & 9 & 15, & 4 & 6,7 \\
Terkontrol) & & o & & \\
10 (Berat Tidak & 1 & 1,7 & o & o \\
Terkontrol) & & & & \\
\hline
\end{tabular}

Berdasarkan tabel 3 terlihat bahwa tingkat nyeri dismenore sebelum intervensi yang paling paling 
banyak dialami responden adalah pada kategori nyeri sedang sebanyak 31 responden (51,7\%). Sedangkan tingkat nyeri setelah perlakuan yang paling banyak pada kategori tidak nyeri sebanyak 28 responden $(46,7 \%)$.

\section{TABEL 4.}

Uji Normalitas Data Nyeri Dismenore pada Kelompok Intervensi dan Kelompok Kontrol

\begin{tabular}{cll}
\hline Uji normalitas & \multicolumn{2}{c}{$p$ value } \\
\cline { 2 - 3 } Tingkat nyeri & Intervensi & Kontrol \\
\hline Sebelum & 0,095 & 0,266 \\
Sesudah & 0,000 & 0,347
\end{tabular}

Berdasarkan tabel 4 menampilkan hasil distribusi data tingkat nyeri dismenore pada remaja putri sebelum intervensi dan sesudah intervensi pada kelompok kontrol menyatakan berdistribusi normal dengan $p$ value $>0,05$. Namun untuk uji normalitas sesudah intervensi data menunjukkan $\mathrm{p}$ value $0,000<0,05$ yang berarti data tidak normal dengan menggunakan test Kolmogorov-Smirnov.

Perbedaan Nyeri Dismenore Sebelum Pretest dan Sesudah Post Test pada Kelompok Intervensi Menggunakan Uji Wilcoxon.

TABEL 5.

Perbedaan Nyeri Dismenore Sebelum Pretest dan Sesudah Post Test pada Kelompok Intervensi

\begin{tabular}{lccc}
\hline Variabel & $\mathrm{n}$ & Mean $\pm \mathrm{SD}$ & p value \\
\hline Sebelum & 30 & $5,13 \pm 3,99$ & 0,000 \\
Sesudah & 30 & $0,13 \pm 1,60$ & \\
\hline
\end{tabular}

Berdasarkan tabel 1.5 nilai $p$ value $=0,00<a(0,05)$. Maka dapat disimpulkan terdapat perbedaan nyeri dismenore sebelum dan setelah pada kelompok intervensi dimana nilai rata-rata sebelum diberikan peregangan (stretching) rata ratanya 5,13 $\pm 3,99$ dan setelah diberikan peregangan (stretching) rata rata nyerinya turun menjadi $0,13 \pm 1,60$. Perbedaan Nyeri Dismenore Sebelum Pretest dan Sesudah Post Test pada Kelompok Kontrol.

Tabel 6.

Perbedaan Nyeri Dismenore Sebelum Pretest dan Sesudah Post Test pada Kelompok Kontrol Menggunakan Uji Wilcoxon

\begin{tabular}{lccc}
\hline Variabel & $\mathrm{n}$ & Mean $\pm \mathrm{SD}$ & p value \\
\hline Sebelum & 30 & $4,60 \pm 1,54$ & 0,o80 \\
Sesudah & 30 & $4,53 \pm 1,52$ & \\
\hline
\end{tabular}

Berdasarkan tabel 6 nilai $p$ value $=0,083>a(0,05)$. Maka dapat disimpulkan tidak terdapat perbedaan tingkat nyeri disminorrhea sebelum dan setelah pada kelompok kontrol. Dimana nilai rata-rata sebelum diberikan 4,60 $\pm 1,54$ dan setelah menjadi 4,53 $\pm 1,52$.
Perbedaan perubahan skor nyeri antara kelompok intervensi dan kelompok kontrol dapat di lihat melalui grafik dibawah ini :

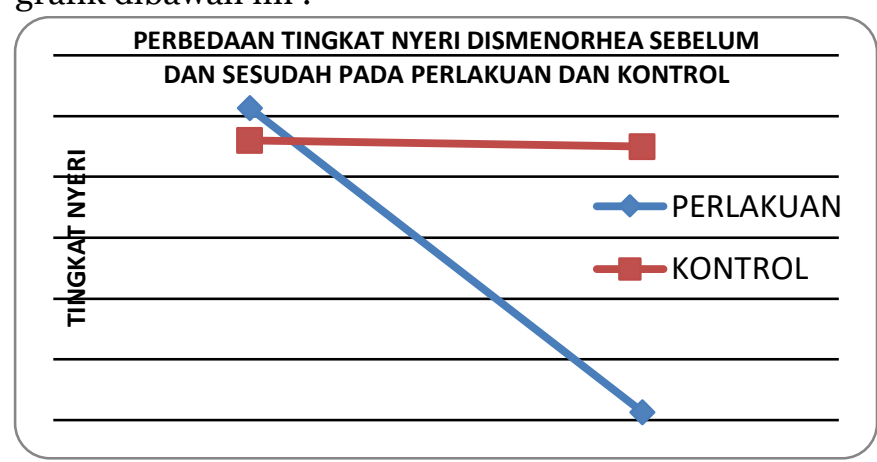

Gambar 1. Grafik Perbedaan Penurunan Nyeri Dismenore Sebelum dan Sesudah Pada Kelompok Intervensi dan Kelompok Kontrol

Perbedaan Pengaruh Peregangan (Stretching) Terhadap Nyeri Dismenore

TABEL 7.

Perbandingan Selisih Nyeri Dismenore Setelah Intervensi pada Kelompok Kontrol dan Kelompok Intervensi

\begin{tabular}{lccccc}
\hline \multirow{2}{*}{ Kelompok } & \multicolumn{2}{c}{ Setelah } & $\Delta$ & Mean & $p-$ \\
& \multicolumn{2}{c}{ Intervensi } & Mean & Rank & valu \\
& Mean & SD & & & $e$ \\
\hline Kontrol & 4,53 & 1,60 & $-4,4$ & 45,32 & 0,00 \\
Intervensi & 0,13 & 0,57 & & 15,68 & 0 \\
\hline
\end{tabular}

Berdasarkan hasil uji Mann Whitney pada tabel 4.7 pada kelompok kontrol dan kelompok intervensi didapatkan p-value sebesar o,00o $(a<0,05)$ menunjukkan bahwa terdapat perbedaan antara kelompok kontrol dan intervensi terhadap penurunan tingkat nyeri dismenore dimana rata-rata tingkat nyeri dismenore pada kelompok kontrol sebesar 4,50 sedangkan pada kelompok intervensi rata ratanya hanya sebanyak 0,13 sehingga didapatkan $\Delta$ mean sebesar $-4,37$. Hal ini membuktikan bahwa pemberian peregangan (stretching) lebih berpengaruh terhadap penurunan tingkat nyeri dismenore dibandingkan yang tidak dilakukan peregangan (stretching).

Tabel 1.8 Pengaruh Variabel Luar Terhadap Nyeri Dismenore

TABEL 8.

Pengaruh Variabel Luar Terhadap Nyeri Dismenore

\begin{tabular}{lccc}
\hline Variabel & p-value & CC & N \\
\hline Umur & & & \\
Remaja & 0,000 & 0,519 & 60
\end{tabular}

\section{Pendidikan}

SMP

0,000

0,481

60

SMA

Mahasiswa 
Berdasarkan tabel 8 hasil analisis bivariat uji korelasi didapatkan bahwa kedua variabel luar mempunyai nilai $p$ value < 0,25 yaitu umur dengan nilai $p$ value 0,000 dan pendidikan dengan nilai $p$ value o,ooo. Dengan demikian kedua variabel luar ini dapat lanjut ke pemodelan multivariat. Model Persamaan Linier Penurunan Nyeri Dismenore.

TABEL 9.

Model Persamaan Linier Penurunan Nyeri Dismenore

\begin{tabular}{|c|c|c|c|}
\hline Variabel & $\begin{array}{l}\text { Model I } \\
\text { (coef 95\% } \\
\text { CI) }\end{array}$ & $\begin{array}{l}\text { Model II } \\
\text { (coef 95\% } \\
\text { CI) }\end{array}$ & $\begin{array}{l}\text { Model III } \\
\text { (coef 95\% } \\
\text { CI) }\end{array}$ \\
\hline \multicolumn{4}{|l|}{ Peregang } \\
\hline & $-4,597$ & $-4,655$ & $-4,367$ \\
\hline Perlakuan & $(-5,270-(-$ & $(-5,342-(-$ & $(-4,962-(-$ \\
\hline Kontrol & $3,924)$ & $3,968)$ & $3,771)$ \\
\hline Umur & 0,341 & 0,131 & \\
\hline & $\begin{array}{l}(0,076- \\
(0,606)\end{array}$ & $\begin{array}{c}(-0,031- \\
(0,293)\end{array}$ & \\
\hline \multirow{2}{*}{$\begin{array}{l}\text { Pendidik } \\
\text { an }\end{array}$} & - & & \\
\hline & $\begin{array}{l}0,917 \\
\quad(-1,846- \\
(0,011)\end{array}$ & & \\
\hline $\mathbf{R}^{2}$ & 0,811 & 0,797 & 0,788 \\
\hline
\end{tabular}
multivariat yang dipilih secara statistik, memiliki nilai koefisien regresi peregangan yaitu sebesar 4,597 dengan nilai $95 \%$ CI sebesar -5,270-(-3,924) setelah dikontrol variabel umur dan nilai koefisien regresi umur ibu sebesar 0,341 dengan nilai 95\% CI (o,076-(0,606) dan dikontrol pula dengan variabel pendidikan dengan nilai koefisien regresi pendidikan sebesar 0,917 dan nilai 95\% CI (-1,846-(0,011).

Model 1 ini dipilih karena hasil uji menunjukkan koefisien determinasi (R square) sebesar o,811 artinya bahwa model regresi yang diperoleh dapat menjelaskan $81,1 \%$ variasi variabel dependen tingkat nyeri dismenore. Atau dengan kata lain variable independen (peregangan (stretching) tersebut mempengaruhi variabel tingkat nyeri dismenore sebesar $81,1 \%$ dan sisanya dipengaruhi variabel lain yakni umur dan pendidikan. Hasil analisis diatas secara statistik dapat memperkirakan tingkat nyeri dismenore dengan menggunakan variabel pemberian peregangan (stretching) maka tingkat nyeri dismenore dapat turun 4,597. Hasil akhir analisis multivariate variabel yang secara signifikan berhubungan dengan tingkat nyeri dismenore adalah intervensi peregangan (stretching) sedangkan kedua variabel luar yaitu umur dan pendidikan tidak terbukti mempengaruhi tingkat nyeri dismenore.

\section{SIMPULAN DAN SARAN}

Berdasarkan hasil penelitian yang dilakukan terhadap santri putri di Pondok Pesantren As Salafiyyah, Al Idris dan Assalimiyyah yakni ada pengaruh peregangan (stretching) terhadap penurunan nyeri dismenore pada santri putri di Pondok Pesantren As Salafiyyah Yogyakarta.

Saran bagi tenaga kesehatan Tenaga kesehatan hendaknya menggunakan sistem jemput bola langsung ke remaja melakukan penyuluhan dan penanganan dismenore secara benar salah satunya dengan metode non farmakologis yaitu peregangan (stretching) melalui program yang dimiliki Puskesmas yaitu Poskestren (Pos Kesehatan Pesantren). Dan saran bagi Pondok Pesantren hendaknya meneruskan latihan peregangan (stretching) untuk para santriputrinya yang mengalami dismenore sebagai metode yang aman, praktis dan murah.

\section{UCAPAN TERIMA KASIH}

Tim penulis mengucapkan terima kasih kepada semua pihak yang telah mendukung terlaksananya penelitian ini hingga penelitian ini dapat diterbitkan dan berguna bagi para pembaca.

\section{DAFTAR RUJUKAN}

[1] Andira, Dita. (2010). Seluk Beluk Kesehatan Reproduksi Wanita. Yogyakarta : A Plus Books.

[2] Badan Pusat Statistik, 2010. Data Statistik Indonesia: Jumlah Penduduk menurut Kelompok Umur, Jenis Kelamin, Provinsi, dan Kabupaten/Kota, 2005.

[3] Daley, A.J. (2008). Exercise and Primery dysmenorhoea : a comprehensive and critikal review of of the literature. Port Medicine :Adis data Internasional

[4] Ningsih, et al. (2011). Hubungan Aktivitas Fisik (olahraga) Dengan Tingkat Nyeri Dismenore.

[5] Potter dan Perry. (2010). Fundamental Keperawatan Buku 3. Edisi 7. Jakarta: Salemba Medika

[6] Pusat Data Dan Informasi Kementerian Kesehatan RI. Info Datin. 2014.

[7] Purnamasari, Wulan.(2013).Efektifitas Terapi Farmakologis dan Non Farmakologis Terhadap Nyeri Haid (Dismenore) Pada Siswi. Skripsi. Universitas Tanjungpura. Pontianak.

[8] WHO, 2014. World Health Statistic 20oo. France.

\section{PROFIL PENULIS UTAMA}

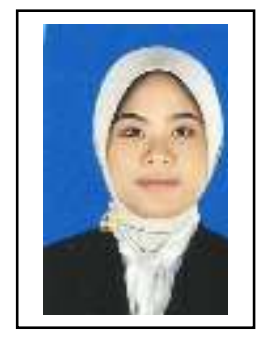

Sherkia Ichtiarsi Prakasiwi, SST, M.Keb, lahir di Semarang 6 Desember 1989, bekerja sebagai Dosen di Universitas Muhammadiyah Semarang. Memulai karirnya pada tahun 2012. Riwayat pendidikan menyelesaikan pendidikan S2 di Universitas 'Aisyiyah Yogyakarta dibidang IImu Kebidanan. Penulis dapat dihubungi melalui email:

sherkia@unimus.ac.id 